
of Cyclists

ان ارتباط الفنون بحياة الانسان جعلته دائم البحث و التققيب عن الاساليب الملائمة والمبتكرة و التي يكتشف من خلالها قيم جديدة تساعد على دفع وتطوير القيم الاصلية ذات الطابع المتميز. لهذا يتضمن البحث عرض لاستخدام تقنية الطباعة المضيئة والتى تبعث أضاءة فى الظلام من ملابس قائدي الدراجات الهو ائية بأسلوب الطباعة بالاستنسل كوسيلة بسيطة من وسائل الطباعة وذللك للمساهمة فى تحقيق السلامة والامان وتقليل مخاطر حوادث الطرق ليلا. وكوسيلة لتفعيل دور الملابس فى تشجيع ممارسة الرياضة و المساهمة فى الحد من المشاكل المرورية اثثاء القيادة ليلا ــ و تكمن اهمية البحث فى تقديم مقترحات ملبسية حديثة تتماثى مع متطلبات عصرنا الحالى. وكذللك تقديم ملابس ذات طابع خاص مضيئة ليلاً . ايضا فتح افاق جديدة نحو التجريب من خلال تقديم افكار طباعبه نفعية لملابس قائدى الدراجات الهوائية ـ و تفعيل دور الملابس فى التشجيع على ممارسة الرياضية من خلال تقديم مقترحات ملبسية جديدة باستخدام تقنيات حديثة. و هدف البحث الى تقيم عدد من التصميمات الملبسية التيشيرت المطبوع باسلوب الطباعة المضيئة تصلح للذكور و الاناث و النى بلغ عددهم "ب ا" تصميم و واعداد استمارة تحكيم للسادة المتخصصين فى بـ مجال الملابس و النسيج و كذللك الفئة المستهدفة " قائدى الدراجات الهو ائية " للتأكد من تحقيق الجو انب الجمالية و الوظيفية للصياغات التصميمية والطباعة المقترحة. مع وجود فروق ذات دلائل احصائية بين التصميمات والصياغات الطباعية المقترحة باستخدام تقنية الطباعة المضيئة .و فروق ذات دلائل احصائية بين التصميمات من حيث تو افر الجانب الجمالي و الوظيفي لصالح عينة البحث. وبالتالي توصل البحث الى امكانية اضافة قيم جمالية وتتكيلية لملابس قائدي الدراجات الهو ائية من خلال استخدام تقنية الطباعة المضيئة وذلك من خلال تحقيق فروض البحث وتحلبلها إحصائيا.

\title{
Abstract:
}

The association of arts with human life has made him constantly researching and exploring appropriate and innovative methods through which he discovers new values that help advance and develop the original values of a distinct character.

the research includes a presentation of the use of luminous printing technology that emits lights in the dark from the clothes of cyclists by stencil printing method as a simple method of printing in order to contribute to achieving safety and security and reducing the risks of road accidents at night. The importance of research lies in presenting modern clothing proposals that are in line with the requirements of our current time. And Opening new horizons towards experimentation by introducing utilitarian typographical ideas for cyclists clothes. And as a way 
to activating the role of clothing, textiles in encouraging the practice of sports by submitting new clothing proposals using modern technologies. The aim of the research is to present a number of clothing designs for the printed T-shirt in a luminous print style suitable for males and females, whose number reached "12". Designing and preparing an arbitration form for the specialists in the field of clothing and textiles, as well as the target group cyclists to ensure that the aesthetic and functional aspects of the design formulas and printing are achieved. Consequently the research reached the possibility of adding aesthetic and plastic values to the clothes of cyclists through the use of luminous printing technology by achieving the research hypotheses and analyzing them statistically.

\section{Key World:-}

- Illuminating Printing- Aesthetic Values -Clothing Of Cyclists

المقدمة :- المكرون

انتشر هو اية ركوب الدراجات الهو ائية بشكل كبير في كثير من الدول الاوربية والغربية بسبب الاجواء الباردة التي تميز المنطقة طو ال العام .ولركوب الدراجة الهوائية الكثير من الفوائد منها البيئية او الصحية هذا وقد اخذت الدراجة الهوائية

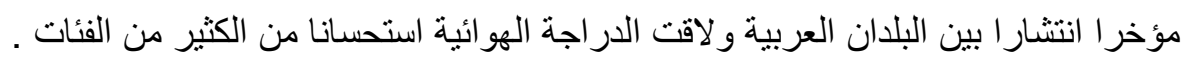

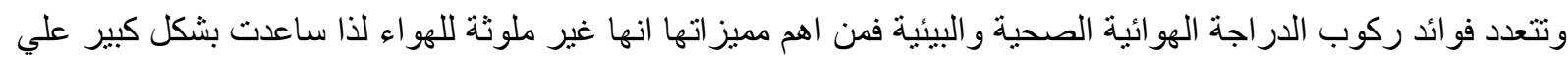

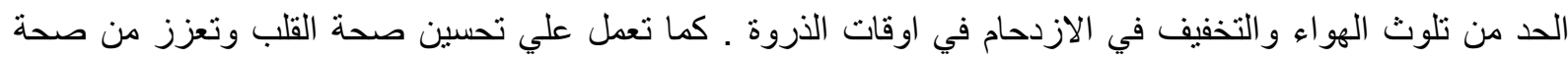
الاوعية الدموية. كما تساعد ركوب الدراجات علي زيادة مرونة عضلات الجسم وخفض نسبة التونر و الحد من الثعور بالاكتئاب كما انها رياضة مميزة لتحسين قو ام الجسم .لذلك اصبحت من الرياضات التي تهتم بها الدولة . كما تعد طباعة المنسوجات من المجالات الفنية الهامة التى يمكن ان تسهم بشكل مبانشر فى التفاعل المستمر مع المجتمع

حيث انها من اهم المجالات التطبيقية التى يمكن من خلالها تقديم منتجات نفعية ذات قيم جمالية متميزة (1')

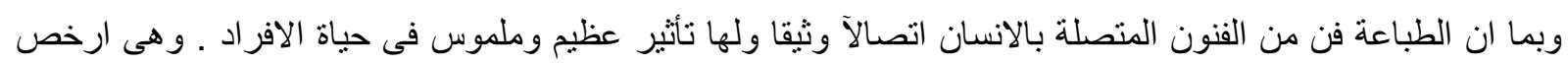
و اسهل الوسائل و اكثر ها استخداما للحصول على تصميم او رسوم متعددة على سطح القماش مقارنة بما يمكن الحصول علية بالخيوط المصبو غة المنسوجة فى الاقشة ( التطريز )( r ) لذا اهتم البحث الحالي باستخدام هذة التقنية ويعد التجريب فى مجال طباعة المنسوجات من اهم الضرورات التى تحقق اهداف هذا المجال ويأتى التجريب فى اتجاهين الاول : يحقق جو انب ابتكارية و الثانى : يتعلق بجوانب تقنية و لاغنى لاحداهما في بناء العمل الفني ('l') مشكلة البحث :يتعرض قائدي الدراجة الهو ائية وخاصة اثناء القيادة ليلا لبعض المشاكل و المخاطر التى تسبب احيانا حوادث اثثاء القيادة. ونظر الانتشار هذا النوع من الرياضة كو سيله رياضية ووسيله مو اصلات امنه بيئيا و اقتصاديا(تكلفتها منخفضة) لذا اتجهت الباحثة الى دراسة دور الملابس فى التشجيع لممارسه تلك الرياضة و المساهمة فى تقليل مخاطر الحوادث المرورية اثناء القيادة ليلا وذلك من خلال صياغة المشكلة البحثية لتجيب على الاسئلة الاتية : 1) ما امكانية الاستفادة من تقنيات الطباعة المضيئه لدعم ملابس قائدى الدرجات الهوائية ؟ 2) ما امكانية اضافة قيم جمالية وتشكيلية لملابس قائدى الدرجات الهو ائية من خلال استخدام تقنيه الطباعة المضيئة ؟ 
3) ما مدى مساهمة تقنية الطباعة المضيئة فى تحقيق عامل السلامة والامان من خلال استخدام ملابس ذات طابع خاص لئ

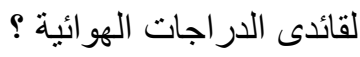

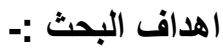

تنضح اهداف البحث فى :-

1. الاستفادة من تقنيات الطباعة المضيئة فى اضافة صياغات جمالية جديدة لملابس قائدى الدر اجات الهو ائية 2. مساهمة الملابس فى تحقيق الامان و السلامة وتقليل مخاطر حو ادث الطرق لقائدي الدر اجات الهو ائية ليلا . 3. تقديم ملابس ذات طابع خاص باستخدام تقنيات الطباعة المضيئة و التى تساهم فى التشجيع على ممارسه رياضة ركوب

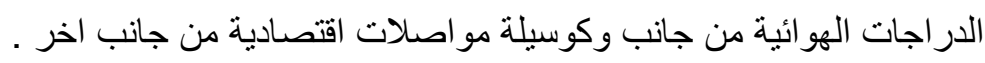

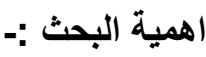

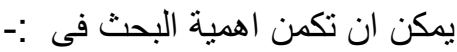

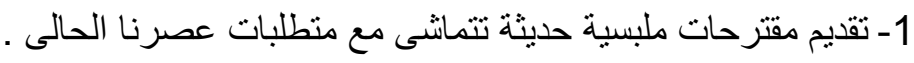

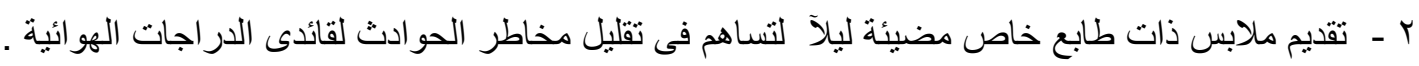
r- فتح افاق جديدة نحو التجريب من خلال تقديم افكار طباعبه نفعية لملابس قائدى الدر اجات الهوائية . ـ -تفعيل دور الملابس و النسيج فى التشجيع على ممارسة الرياضية من خلال تقديم مقترحات ملبسية جديدة باستخدام تقنيات

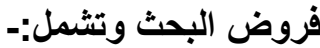

1) هنالك فروق ذات دلائل احصائية بين التصميمات والصياغات الطباعية المقترحة باستخدام تقنية الطباعة المضيئة. 2) هنالك فروق ذات دلائل احصائية بين التصميمات والصياغات المقترحة من حيث تو افر الجانب الجمالي (اسس و عناصر (التصميم) 3) هناك فروق ذات دلائل احصائية فى مدى مساهمة الملابس المقترحة فى تحقيق الجانب الوظيفى لقائدى الدراجات الهو ائية. ء) يتحقق فى الصياغات الملبسية المنفذة بتقنيه الطباعة المضيئة عامل الامان و السلامة وتقليل المخاطر (الجانب الوظيفى).

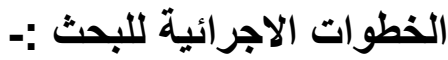

اولا منهج البحث : الاجن : أ. المنهج الوصفى :- اتبع البحث المنهج الوصفى لاستطلاع ار اء كلا من المتخصصين و المستهلكين فى تقديم ملابس ذات

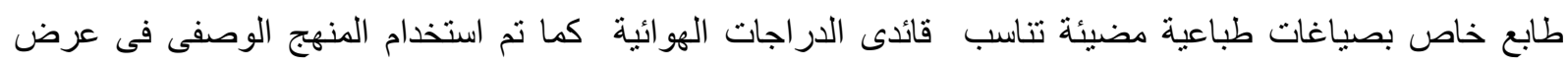
الدر اسات المرتبطة بالبحث وكذللك الاطار النظرى.

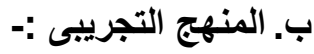
وذللك من خلال تقديم تصميمات بصياغات جديدة ذات طابع خاص تناسب قائدى الدر اجات الهو ائية . ثنانيا ادوات البحث :أ. استبيان لاستطلاع ار اء السادة المتخصصين فى مجال الملابس و النسيج وكذلك المستهكين " قائدى الدراجات الهو ائية " فى مجمو عة التصميمات و الصياغات الملبسة المقترحة سو اء جماليا او وظيفيا ب. استخدام برنامج الفوتوشوب مhoto shop cc 2017 فى تصميم المقترحات الملبسية واعطاءها التاثير ات المختلفة

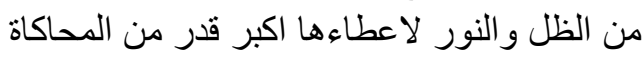

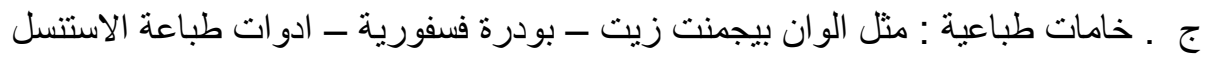


ت.وصف عينة البحث : اشتملت عينة البحث على مجموعة من المتخصصين فى مجال الملابس والنسيج وعددهم (1) بينما المستهلكين و عددهم ( ؟Y) مقسمة الى مجمو عتين الاولى : تحتوى على عدد (10) من الذكور

" الثانية : تحتوى على عدد (9) من الاناث و التى تتراوح اعمار هم من 10 : ـ سنة ـ ويقيمون بمحافظة اسيوط وذللك

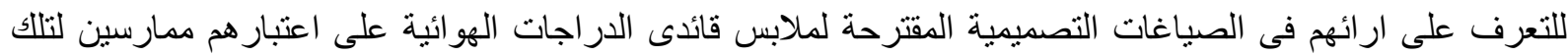
الرياضة .

\section{رابعا مصطلحات البحث:-}

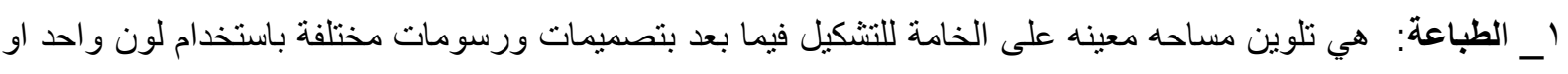

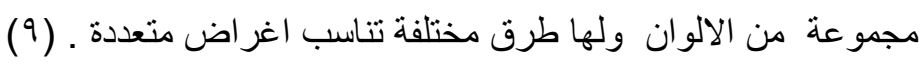

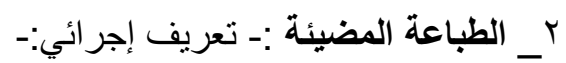
هو اضافة زخرفه ووحدات تصميمية علة الاقمشة المختلفة بطرق بسيطة من تقنيات الطباعة التقليدية مستخدما عجائن او الوان مضيئة تبعث أضاءه في الظلام بـ_قيم تثكيلية:- هي تللك الاسس التي يوجدها التز امنا التلقائي بها في اعمالنا الفنية عند تشكيلها و عند حكمنا عليها وترتبط

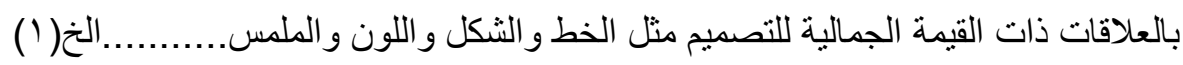

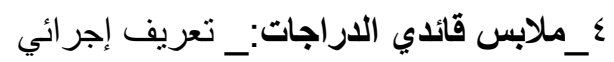
هي كل ما يرتديه الفرد من مفردات ملبسيه ويستخدمها اثثاء ممارسة قيادة الدراجة الهوائية مثل (التي شيرتـ القميص-

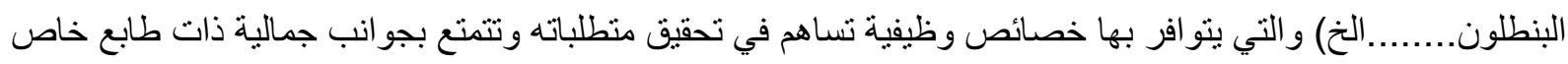
- در اسة (ايمان صلاح حامد _N ( • rم) و التي هدفت الى استخدام التقنيات الطباعية اليدوية لإبر از قيم جمالية لعناصر الفن الإسلامي وتطبيقها على اقمشة التأثيث

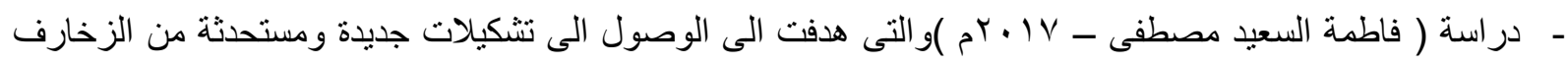
باستخدام الطباعة بالإز الة لزخرفة ملابس الاطفال لأثر اء القيم الجمالية لملابس الاطفال ولخدمة المشرو عات الصغيرة .

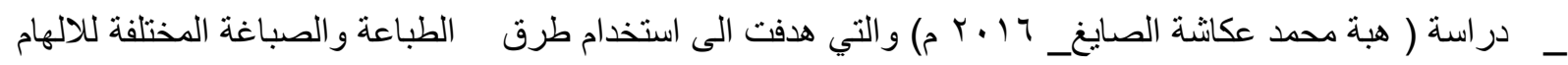

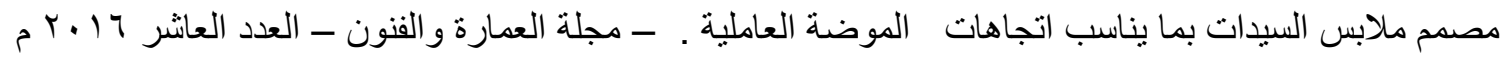

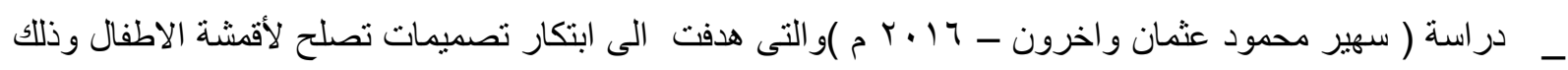
بدر اسة اتجاهات الموضة العالمية لاقشة الاطفال المطبوعة لربيع / رصيف 17 ـ بر لتساير احدث اتجاهات الموضة العالمية من حيث الجودة و الذوق الفنى - تطبيق بعض اساليب طباعة المنسوجات بتقنيات وتكنولوجيا حديثة امنة بيئيا 


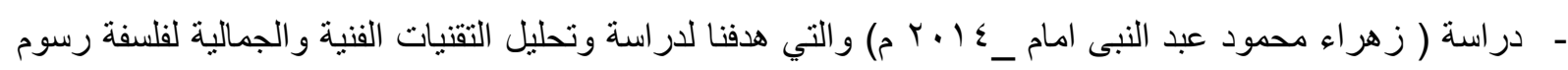
اطفال العالم و ابتكار تصميمات تصلح طباعتها على اقشة ملابس الاطفال للوصول الى منتج مطبوع تكون بها صدى عميق فى نفوس الاطفال لانها الاقرب الى اذهانهم .

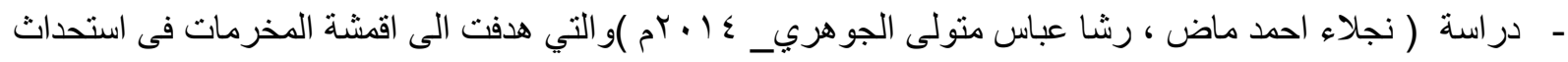
تصميمات طباعية كمدخل تجريبى للطباعة اليدوية لخدمه الصناعات الصغيرة

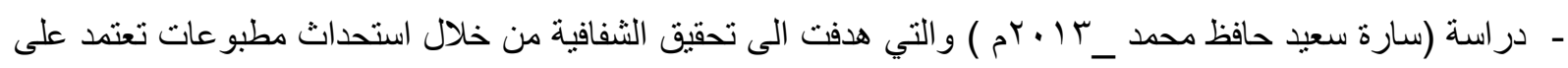

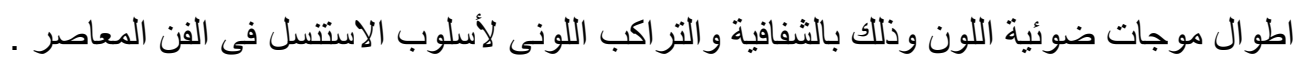

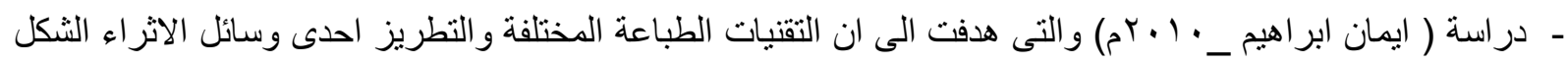
الجمالى والوظيفى لتصميمات الملبسية حيث انها تجمع بين الناحية الجمالية والمهارة اليدوية مما يجعلها طبعة لأساليب الابتكار في التصميم وطرق التنفيذ بشكل بثرى المنتجات الملبسة

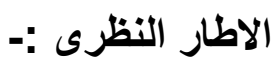
يتطور مجال تصميم الازياء بصورة سريعة مستخدما كل مستحدثات العصر من الاساليب الفنية الحديثة والتكنولوجيا المنطورة و التقنيات و الخامات الجديدة . لذا يعتبر مجال تصميم الازياء من المجالات سريعة التغير نتيجة للابتكارات والتجديدات المستمرة .

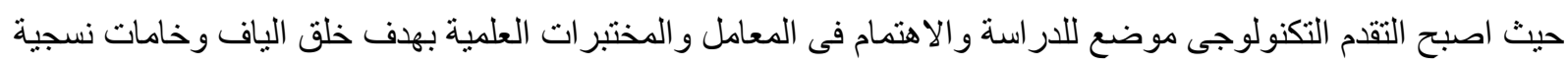
حديثة ذات خو اص جمالية ووظيفة واداء عالى الجودة يستخدم فى صناعة الازياء. .

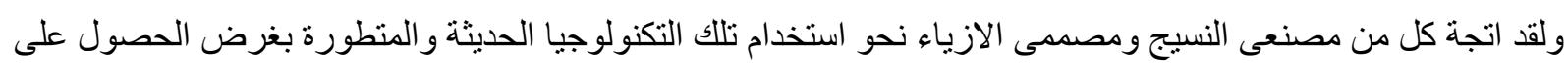
وظائف ملبسية جديدة فقد اصبح مفهوم الذكاء الاصطناعى للازياء مرتبطآ بالعديد من مقومات حياتتا خاصة الملبس .

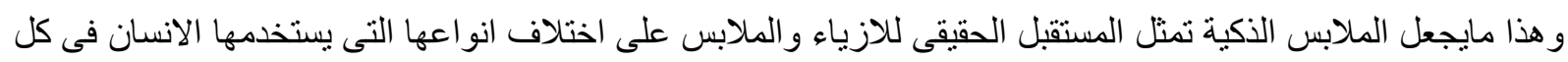
مكان وخاصة مايسمى بالملابس الوظيفية التى تتطلب فى استخدامها توفير مستوى عالى من خواص الاداء تبعاً لنوع

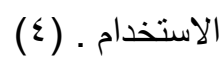
و استطاعت التقنيات الذكية الدخول بقوة فى مجال التصميم الازياء وفرض على المصمم الكثير من التحديات حيث امكن استخدامها بشكل جمالى ووظيفى فى عروض الازياء العالمية . لذا فقد حقق هذا المجال الكثير من التطبيقات العلمية والفنية

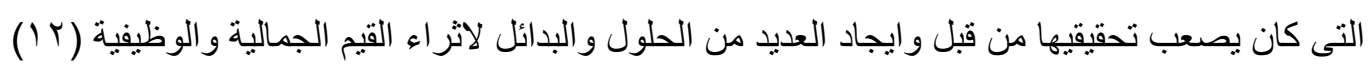
الخامات الأكية :- الخبات اكتسبت الخامات صفة الذكاء نظر الانها يمكنها ان تشعر بالظروف البيئية المحيطة بها او المتواجدة فيها بالاضافة الى

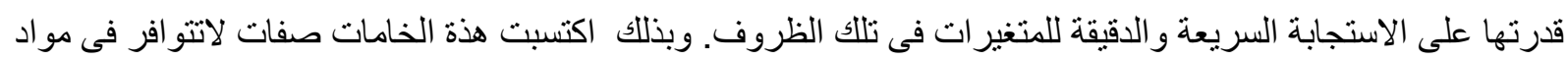
او منسوجات اخرى ـ كذللك يمكنها استعادة حالتها الاولى سواء كانت الثكل او اللون او الابعاد بعد زوال التهابل التغيرات البيئة (المحيطة بها . (T) (1T)

من الهم الخامات الأكية المستخدمة فى مجال الملابس والنسيج: -

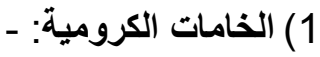
و هى تللك الخامات التى تشع لون اونة يزول لونها ويتغير لونها عند حدوث مؤثرات خارجية عليها. وتصنف هذة المواد تبعاً لنوع المحفزات التى تؤثر عليها. 


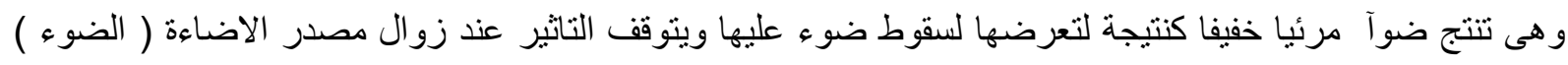
وتكون الصبغات المشبعة المنتجة من هذة المو اد ذات لون ضعيف او بيضاء فى ضوء الثمس بينما عند اثارتها بالأشعة فوق البنفسية تضئ لون مشع مركز فى الظلام وفى معظم الحالات يكون الضوء المنبعث طول موجى اطول وبالتالى طاقة اقل من الاشعاع الممتص .( (7) و التي تم استخدامها في تقنيه الطباعة في البحث الحالي.

\section{طباعة المنسوجات :- ماتر} هى الطريقة التى يمكن بها الحصول على نماذج او رسومات ملونه بطريقة مختلفة على شتى انو اع الاقمشة المعروفة من قطن وصوف وحرير طبيعى وكتان او مخاليط من هذة الالياف. وهى ايضاً عملية تلوين موضعى فى حدود الزخرفة او الرسم المطلوب اخر اجة وتتفيذة على الاقمشة بواسطة الطباعة او الصباغة او الرسم (· ( )

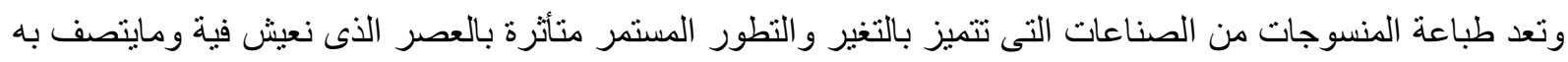
من خصائص تشكيلية جديدة والتى تتنوع وتتعدد الاساليب و المفاهيم و الرؤى التتكيلية فيها لتصميم طباعة المنسوجات تبعاً

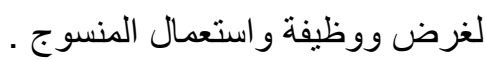
ومن اسس التصميم ان يقوم الفنان بتنظيم وتتسيق مجموع عناصر التصميم بما يجعلها تؤثر ناثثير آ فعالآ يرقى بالتصميم من كونة جامدآ الى كونة متزنا اتز انا ايهامياً يخلق فى التصميم نو عآ من الحركة الادر اكية . ( ع ( ) وتعتبر طباعة الاقمشة من اشهر صناعات النسيج واكثرها ارتباطآ بالنواحى الجمالية ـ. وكانت الرغبة فى تنزين الاقمشة بالرسوم الملونة موجودة منذ اقدم العصور اذ ان الاقمشة المطبوعة ظهرت قبل الاقمشة المنسوجة بالالوان و المطرزة . وتدرجت هذة الصناعات من استخدام ابسط المعدات الى استعمال اعقد الماكينات خلال الاف السنين . كما يعد التجريب فى مجال طباعة المنسوجات من اهم الضرور ات التى تحقق اهداف هذا المجال .

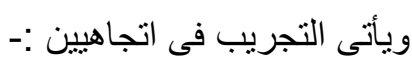
الاول : يتعلق بتحقيق جو انب ابتكارية . الثنانى : يتعلق بجو انب تنقنية. و لاغنى لاحد الحالتين فى بناء العمل الفنى اذا لايتحقق الجانب الجمالى دون التحكم فى التقنيات اللازمة كما انها لاقيمة للجوانب التقنية دون قدرتها على تحقيق قيم جمالية خاصة ( ) طرق الطباعة المختلفة :- تلبرة تعتبر الطرق التقليدية اليدوية لطباعة وصباغة المسنوجات من الطرق الثرية جدا لأبداع تصميمات اقمشة ملابس مطبو عة متنو عة ومختلفة عن التصميمات المنو اجدة بالفعل فى الاسواق و التى تعتبر مفروضة بشكل كبير على المصمم رغم تتوعها ـ ولكنة لا بسنطيع ان يقوم بنفسة بابداع تصميم الاقمشة المستخدمة فى تصميم وتنفيذ الملابس الخاصة به تبعا لتخيله 
لذللك نجد ان الطرق اليدوية التقليدية لطباعة المنسوجات تسمح لمصمم الملابس بأبداع تصميمات ذات طابع خاص به ومن هذه الطرق الطباعة بالاستتسل وهى التي تم استخدامها كتقنية طباعية فى البحث الحالى

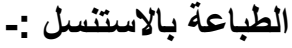

هو تفريغ اي تصميم على ورق او بلاستيك بتقطيع بعض اجز اء التصميم لانز ال اللون من خلالها على القماش وطباعتة .

\section{-:pigments" ملونات البيجمنت (المخضبات)}

ملونات البيجمنت هى عبارة عن صيغات مشتتة (disperse dyes) نم تحضير ها فى صورة معلقات مائية لمو اد ملونة

وتحضر هذة المشتتات بسحق هذة المواد الملونة النقية فى وجود الماء وعامل تشتيت مناسب dispersing agent

باستخدام مطاحن عالية الكفاءة تحقق لنا انسب حجم للحبيبات يضمن زهاء الالو ان و عمقها و علو انتاجها . ويلاحظ ان المواد الزرقاء تحتل حبيباتها اصغر طول قطر بينما تحتل المواد الملونة الحمر اء اكبر طول قطر . . ولقد اختير فى تحضير صبغات البجمينت ارخص المواد الملونة بحيث تحقيق الزهاء وعمق اللون المطلوب مع قلة التكاليف وسهولة تسويق الصبغة .

ويجب ان يتو افق عامل التشتيت المستخدم مع مكونات عجينة الطباعة حتى لا يسبب تجمع لحبيبات الصبغة مع عامل الربط او يتفاعل معه فيعوق انسياب العجينة ويسبب عدم التجانس اللوني على سطح الخامة المطبو عة( ؟).و(V) الالوان المضيئة :هى مركبات فسفورية مصنو عة من مو اد غير عضوية خاملة كيميائيا وامنة بيئياً تتو هج لوقت معين .

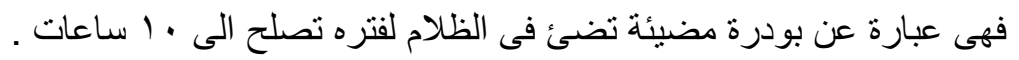
و التى تستمد قدرتها على الاضاءة من خلال تجميع الحبيبات الموجوده للطاقة من الضوء مثل اثعة الثمس و التى تختزنها لتضئ فى الظلام .

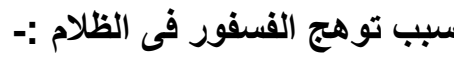
ان استخدام الفسفور كمصدر للأشعاع فى الظلام سبية ان ذرات الفسفور تستقبل الضوء وتختزلة لساعات طويلة من 7 : ب ا ساعة حتى يحل الظلام فتقوم بعكس الضوء التى قامت بتخزينة طول فترة النهار او طول فترة تعرضها للضوء (؟ ) و هذا ما دعا الباحثة الى استخدام هذه اللوان المضيئة لطباعة ملابس تصلح لقائدى الدرجات وخاصـا اثناء القيادة ليلا

اعداد مجمو عة من التصميمات المقترحة لفئة قائدي الدرجات الهو ائية و عددهم ( r ( ) تصميم مقسمين كالاتى : ا/ عدد(7) تصميمات رجالى امام وخلف ويحتوى كل تصميم على وحدة زخرفية مميزة لملابس قائدى الدر اجات الهو ائية

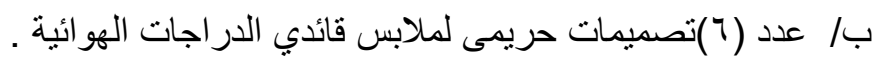
ويحتوى كل تصميم على وحدة زخرفية مميزة لملابس قائدى الدر اجات الهو ائية 


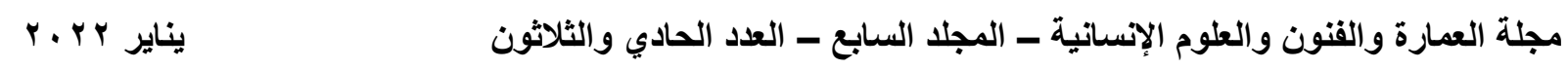
وتم استخدام برنامج الفوتوشوب فى اعداد التصميمات والصياغات الملبسية المقترحة وجاءت التصميمات كالاتى: /الصياغات التصميمية المقترحة لفئة الرجال

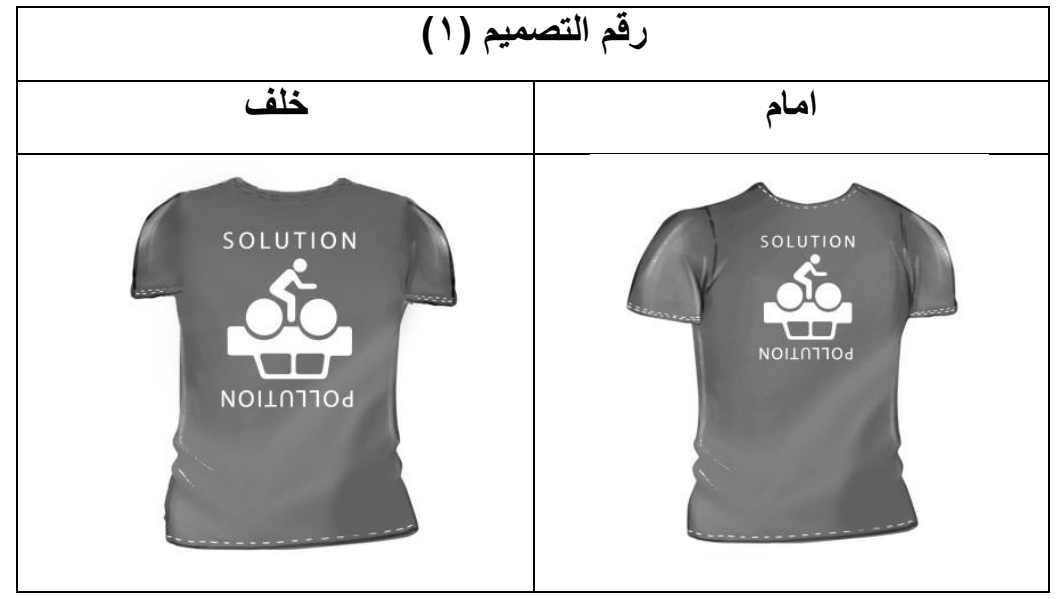

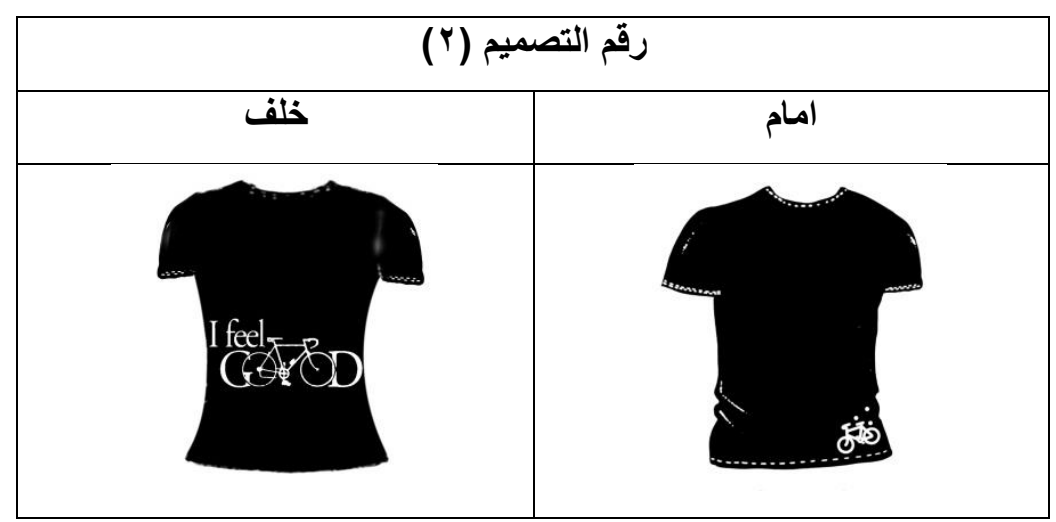

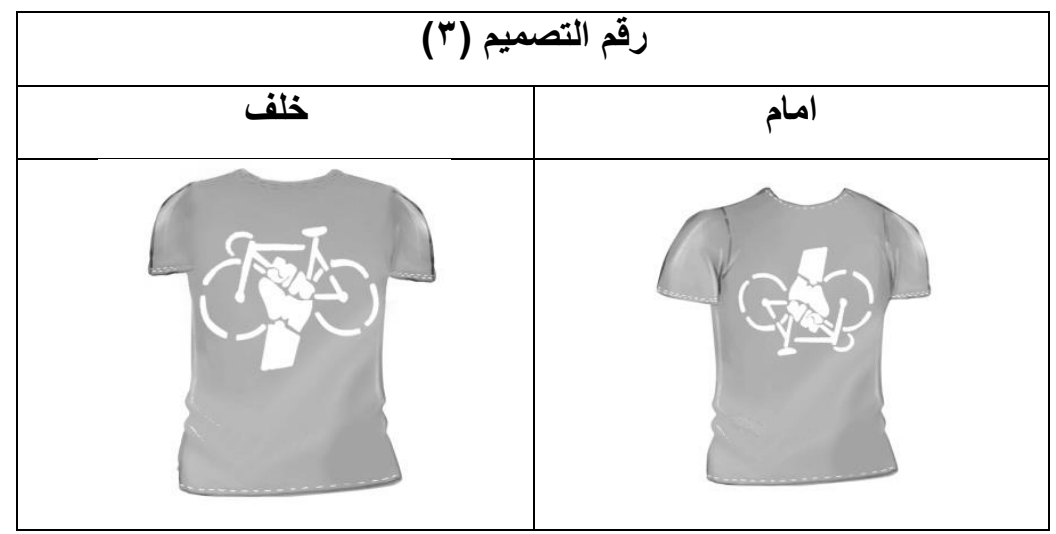

\begin{tabular}{|c|c|}
\hline \multicolumn{3}{|c|}{ رقم التصميم (£) } \\
\hline
\end{tabular}


مجلة العمارة والقنون والعلوم الإنسانية ــ المجلد السابع ـ العدد الحادي والثلاثون

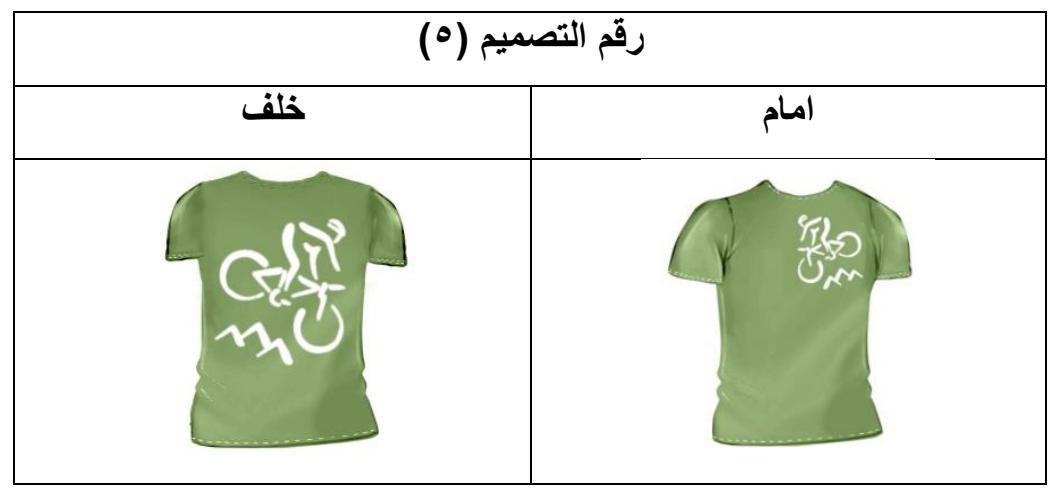

\begin{tabular}{|c|c|}
\hline \multicolumn{3}{|c|}{ رقم التصميم (T) } \\
\hline \\
\hline
\end{tabular}

ب/ الصياغات التصميمية المقترحة لفئة السيدات

\begin{tabular}{|l|l|}
\hline \multicolumn{3}{|c|}{$(\mathrm{V})$ رقم التصميم } \\
\hline \\
\hline
\end{tabular}

\begin{tabular}{|c|c|}
\hline \multicolumn{2}{|c|}{$(\wedge)$ رقم التصميم (م) } \\
\hline \\
\hline
\end{tabular}


مجلة العمارة والفنون والعلوم الإنسانية ــ المجلد السابع ـ العدد الحادي والثلاثون

\begin{tabular}{|c|c|}
\hline \multicolumn{3}{|c|}{ رقم التصميم (9) } \\
\hline خلف \\
\hline
\end{tabular}

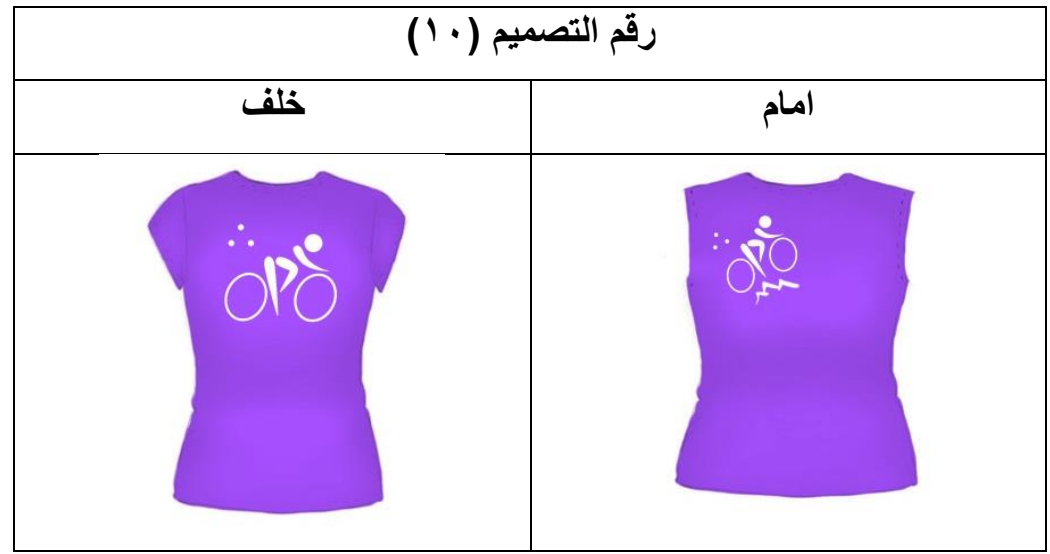

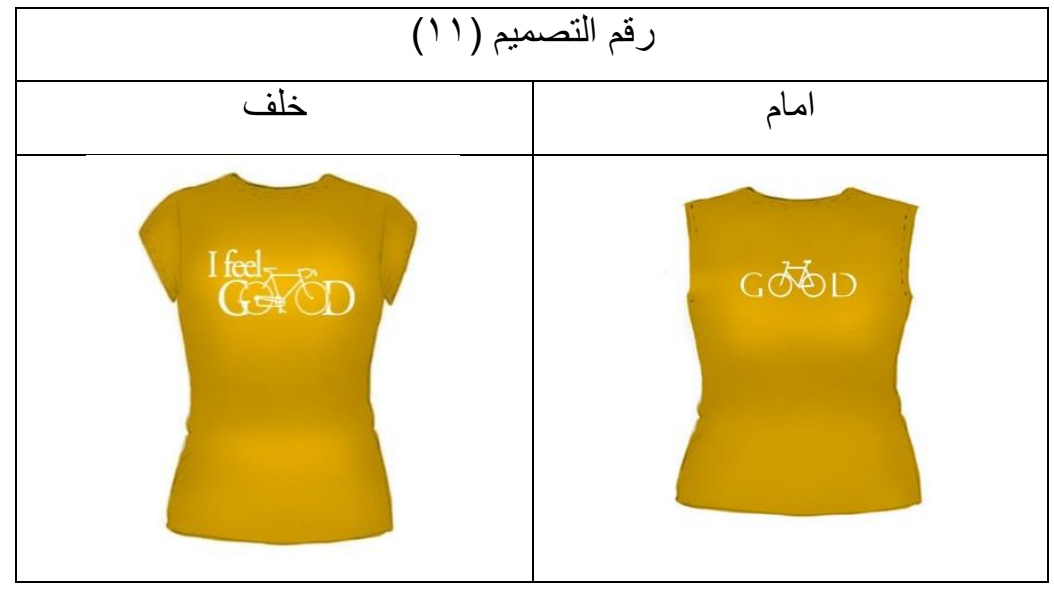

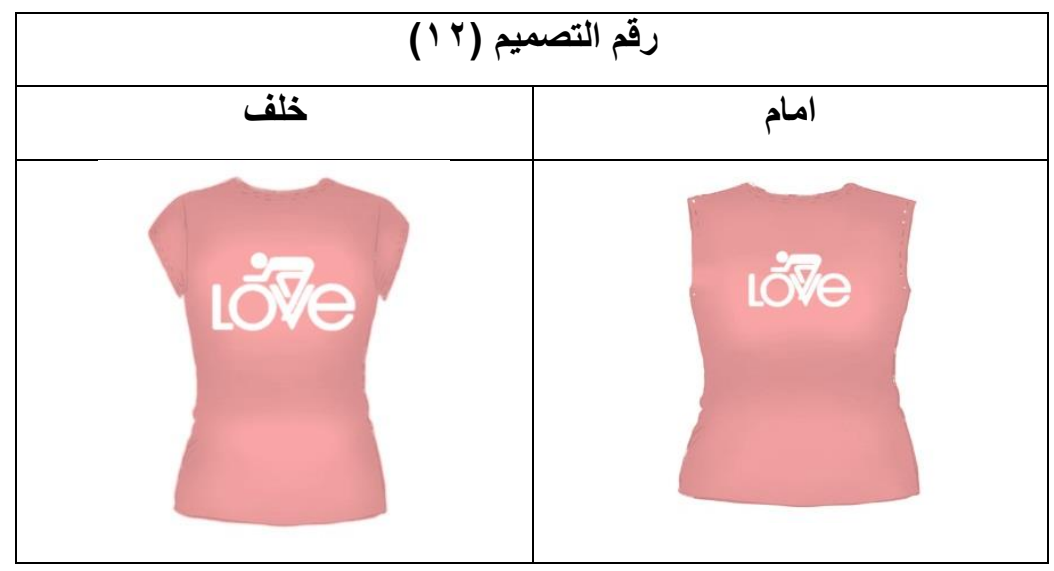


ثنانيا: : تم عرض التصميمات المقترحة على السادة المتخصص فى مجال الملابس و النسيج للتحكيم و الذى بلغ عددهم( (') ) محكم كما تم عرض الاستمارة على المستهلكين و هم قائدى الدراجات الهو ائية و الذى بلغ عددهم (ع ب) مقسمين الى ( 9 من الاناث ) ( 10 من الذكور ) من خلال اعداد استمارة تحكيم لقياس مدى تو افر الجوانب اجمالية و الوظيفية في الصياغات التصميمية المقترحة التي تم تحكيمها لغويا من خلال عرضها على عدد (9) من السادة المتخصصين في مجال الملابس و النسيج للتأكد من سلامه صياغتها ووضوح عبار اتها واحتوت الاستمارة على تقدير خماسي وتكونت من ثناث محاور كالاتي:

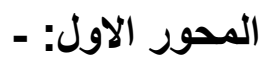

\section{ملائمة الصياغات المقترحة لتحقيق الجاتب الجمالي (تحقيق وتوافر عناصر واسس التصميم) والأي يتضمن البنود الاتية}

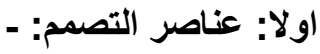

1- ما مدى ملائمة خطوط التصميم للصياغة المقترحة؟

2- ما مدى ملائمة لون التصميم للصياغه المقترحه؟ مأس

3- ما مدى ملائمة شكل التصميم المقترح؟

4- ما مدى وضوح تأثير الخامة فى الصياغات التصميمية المقترحة؟ ملته

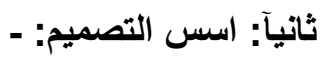

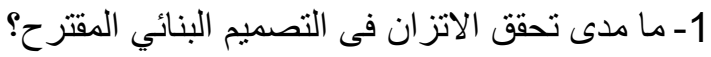

2- ما مدى تحقق الوحدة و الترابط فى الصياغات التصميمية المقترحة؟

3- ما مدى تحقق النسبة والتناسب فى الخطوط المستخدمة بما يخدم الصياغات التصميمية المقترحة؟

4- ما مدى الانسجام و التو افق بين عناصر الصياغات التصميمية المقترحة؟

5- ما مدى تحقيق الايقاع فى الصياغات التصميمة المقترحة؟ ماءع

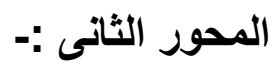

مدى مساهمة الصياغات التصميمية المقترحة فى تحقيق الجانب الوظيفي والأى يتضمن البنود الاتية 1- ما مدى مناسبة الطباعة المضيئة المقترحة لملابس قائدى الدرجات الهو ائية؛؟ .

2- ما مدى مناسبة الوحدة التصميمية المقترحة لاسلوب الطباعة المضيئة .؟

3- ما مدى مناسبة الصياغات الطباعية المضيئة المقترحة للفئة العمرية المستهدفة والتي تتراوح من ( • 10:0 سنه)؟ . 4- الى اى مدى تساهم الصياغات الطباعية المضيئة المقترحة فى تحقيق السلامة والامان تقليل المخاطر الحوادث لسائق

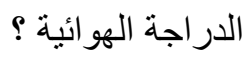

5- ما مدى مساهمة اسلوب الطباعة المقترح فى خدمة افر اد المجتمع و التشجيع على ممارسة الرياضة .؟ ؟ هـ 6- الى اى مدى تتميز الصياغات الطباعية المقترحة بطابع خاص ومميز يميز مرتديها ( الفئة المستهلكة ) ؟

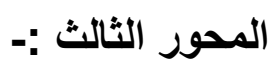

مدى امكانية تنفيذ بعض القطع من الصياغات التصميمية المقترحة والذى يتضمن البنود الاتية:

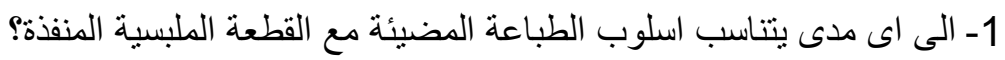

2- الى اى مدى تحتفظ القطعة المنفذة بأضاءتها فى الظلام ( فترة كافية تتر اوح من ؟ : 7 ساعات) ؟

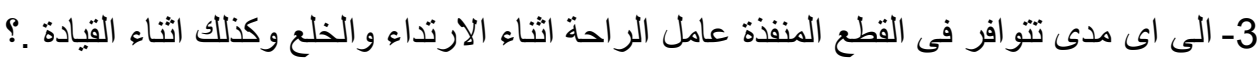


ثالثا :تم عمل التحليلات الاحصائية والتي كانت نتائجها كالاتي للصياغات التصميمية المقترحة. | الصدق والثبات لاستمارة التحكيم أمكن للباحثة التأكد من الخصائص السيكو مترية لاستمارة التحكيم المستخدمة في البحث حيث تم الاستعانة بعدد(9 )من

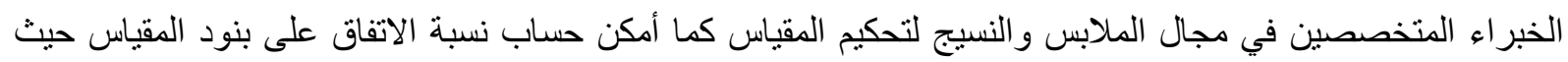

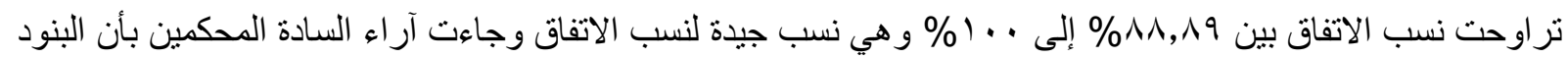
مناسبة ولا يوجد بها تعديل وتقيس ما وضع لقياسه وهو فياس الجانب الجمالي و الوظيفي للصياغات التصميمية الملبسية

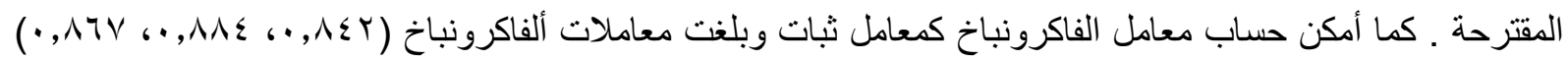
لمحور الجانب الجمالي والجانب الوظيفي والدرجة الكلية للمقياس على التوالي، كما أمكن حساب ثبات الاتساق الداخلي بين

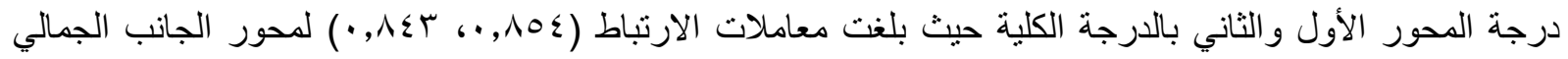
و الوظيفي على التو الي و هي قيم مرتفعة.

ب / تحليل اراء السادة المتخصصين والمستهلكين فى التصميمات المقترحة من حيث الجوانب الجمالية والوظيفية كالاتى جدول ( ) آراء المتخصص في التصميمات المقترحة للحكم على الجوانب الجمالية والوظيفية (ن= I 1 ) )

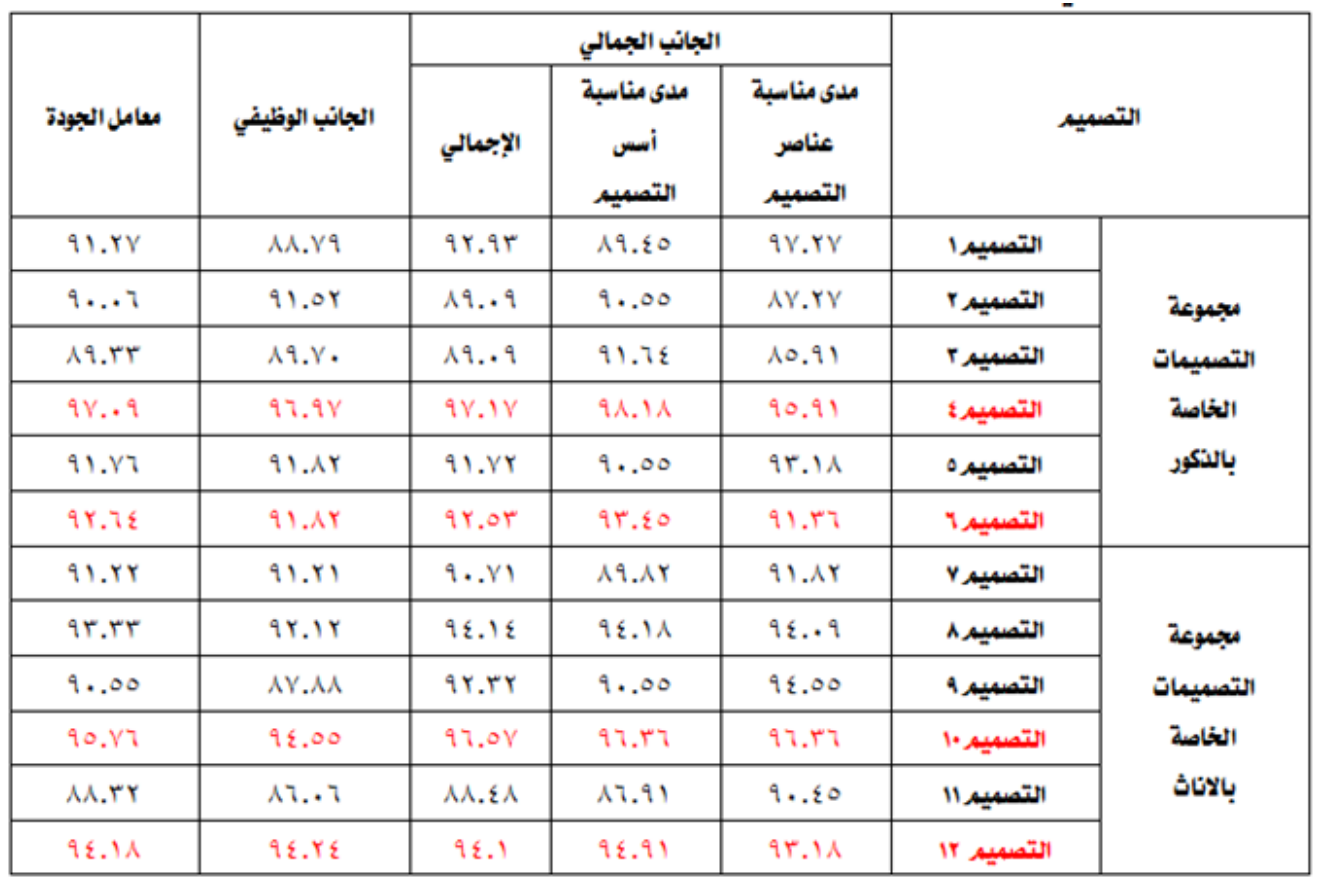

يتضح من خلال الجدول السابق أن التصميمات المقترحة جميعها حصل على معامل جودة عالي تراوح ما بين r ب, M إلى

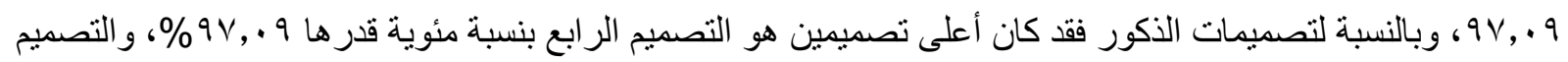
السادس بمعامل جودة قدره ـ ؟, 9\%\%. وكان أقل تصميمين هما التصميم الثالث و الثاني على التوالي بمعامل جودة قدره $\% 9 \cdot,+7$ ،

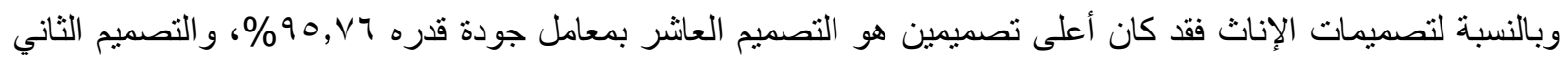

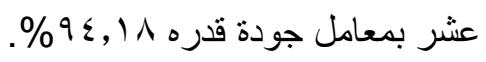

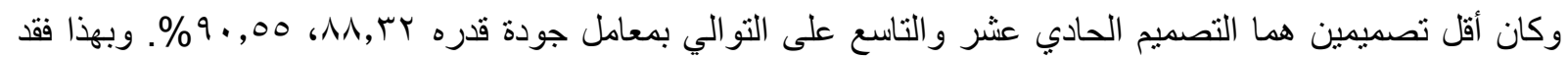
قامت الباحثة باختيار التصميم الأول في مجموعة الذكور ومجموعة الإناث ليتم تتفيذ تصميمين بو اقع تصميم واحد وهو التصميم الأعلى لكل مجمو عة وفق لآر اء المحكمين. 


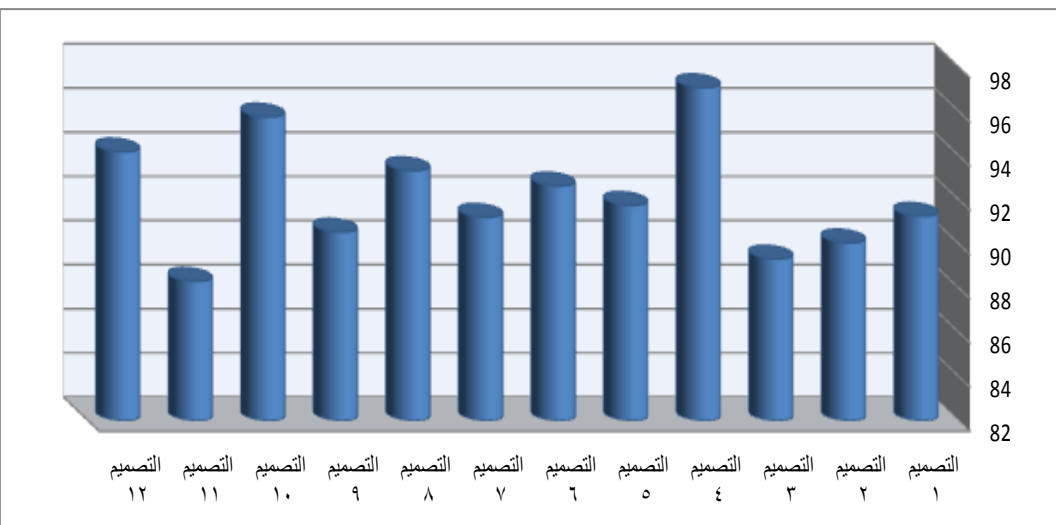

شكل ( ) النسب المئوية لمعامل جودة التصميمات المقترحة بناء على الجوانب الجمالية والوظيفية وفق لآراء المحكمين (ن= 1 )

جلول (Y) آراء المستهلكين في التصميمات المقترحة للحكم على الجوانب الجمالية والوظيفية (ن= ؛ ؟)

\begin{tabular}{|c|c|c|c|c|c|c|}
\hline \multirow[b]{2}{*}{ معامل } & \multirow[b]{2}{*}{ الوأيفي } & \multicolumn{3}{|c|}{ الجانب الجمالي } & \multirow[b]{2}{*}{ التصمير } & \multirow[b]{2}{*}{ المتهلكين } \\
\hline & & الإجعالي & ملى مناسبة & ملى مناسبة & & \\
\hline Ar.tr & qr.VA & $9 T . . \varepsilon$ & $9 r . . V$ & 95 & التصمير' & \multirow{6}{*}{ 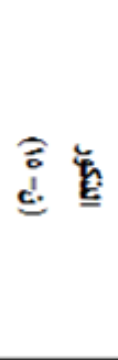 } \\
\hline १1.ro & ᄉ . . & GY.YE & 19.rT & 90 & التصمير r & \\
\hline QY & 9r.TV & 91.07 & १... & 9Y.TY & التصميرr & \\
\hline q..v & $91 . \wedge \mathrm{V}$ & 19.9T & M.or & $91.7 \mathrm{~V}$ & التصمير؛ & \\
\hline 9.. rV & M & 91.4 & 9... V & ar & اتتصميره & \\
\hline 91.1. & $9 Y . .99$ & $9 . .59$ & 9६.ाT & NE.TT & اتتصمير، & \\
\hline 97.9. & 90.95 & 90.1. & 97 & 90.07 & التصمير v v & \multirow{6}{*}{ 竞 } \\
\hline 91.10 & 94.97 & 91.11 & 91.11 & 91.11 & اتتصميرءA & \\
\hline 97.19 & 9v.ह1 & 97.0\{ & 90.07 & 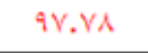 & التصميرج" & \\
\hline १६.TV & 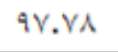 & 9Y.l. & १Y.६६ & $91.7 \mathrm{~V}$ & التصمير•| & \\
\hline NY.rY & Ar.09 & 11.91 & จ१.11 & 10.07 & اتتصمير" & \\
\hline 1..01 & AT.rv & q.. TV & עדוה & 90 & Ir التصمير & \\
\hline
\end{tabular}

يتضح من خلال الجدول السابق أن التصميمات المقترحة جميعها بالنسبة للذكور حصلت على معامل جودة عالي تراوح ما

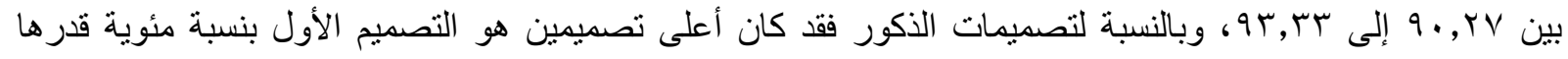

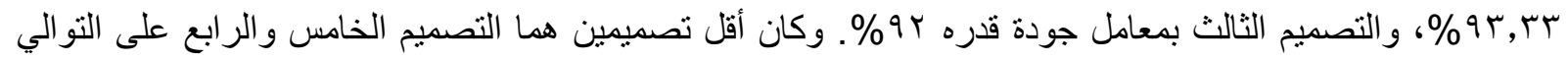

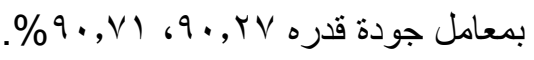
كما يتضح من خلال الجدول السابق أن التصميمات المقترحة جميعها بالنسبة للإناث حصلت على معامل جودة عالي تر اوح

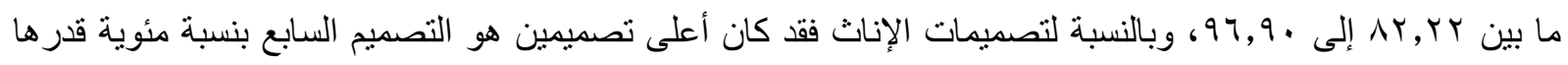
•9, 97\%، و التصميم التاسع بمعامل جودة قدره 9.1, 9\%\%. وكان أقل تصميمين هما التصميم الحادي عشر والثاني عشر

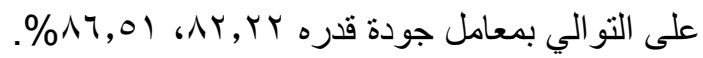
وبهذا فقد قامت الباحثة باختيار التصميم الأول في مجموعة الذكور ومجموعة الإناث ليتم تنفيذ تصميمين بو اقع تصميم واحد و هو التصميم الأعلى لكل مجموعة وفق لآر اء المحكمين. 


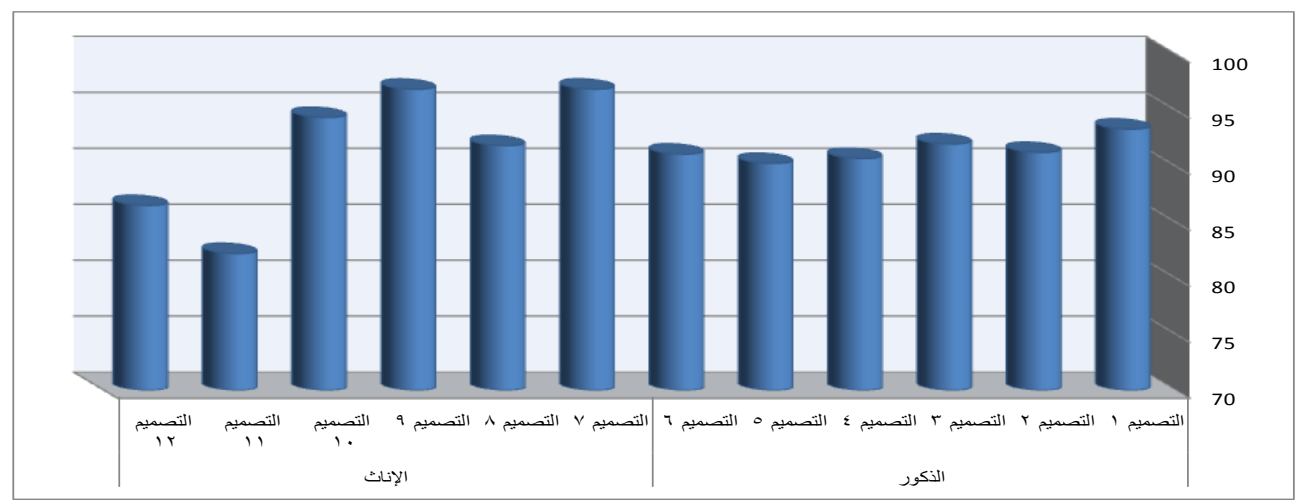

شكل (Y) النسب المئوية لمعامل جودة التصميمات المقترحة بناء على الجوانب الجمالية والوظيفية وفق لآراء المستهلكين (ن= ؛ ؟)

رابعا:

تم اختيار افضل تصميمين فى كل مجمو عة لتنفيذ تقنية الطباعة المضيئة على التى ـ شيرت والتي حازت على اعلى نسبة قبول للمستهلكين (الذكور -الاناث) وجاءت كالاتي : (أ) القطع المنفذة لفئة الأكور:-

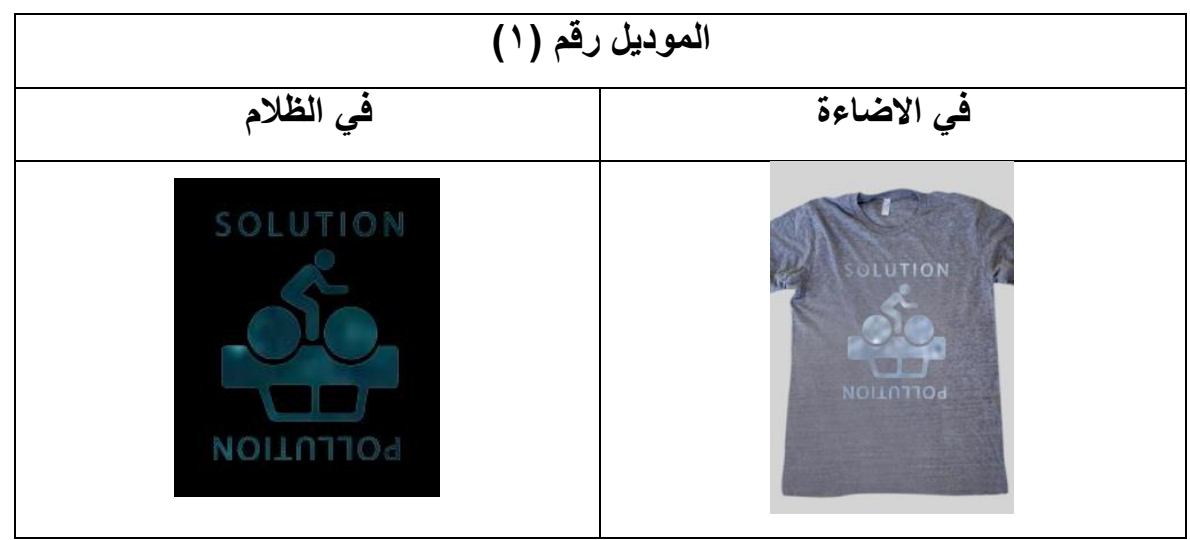

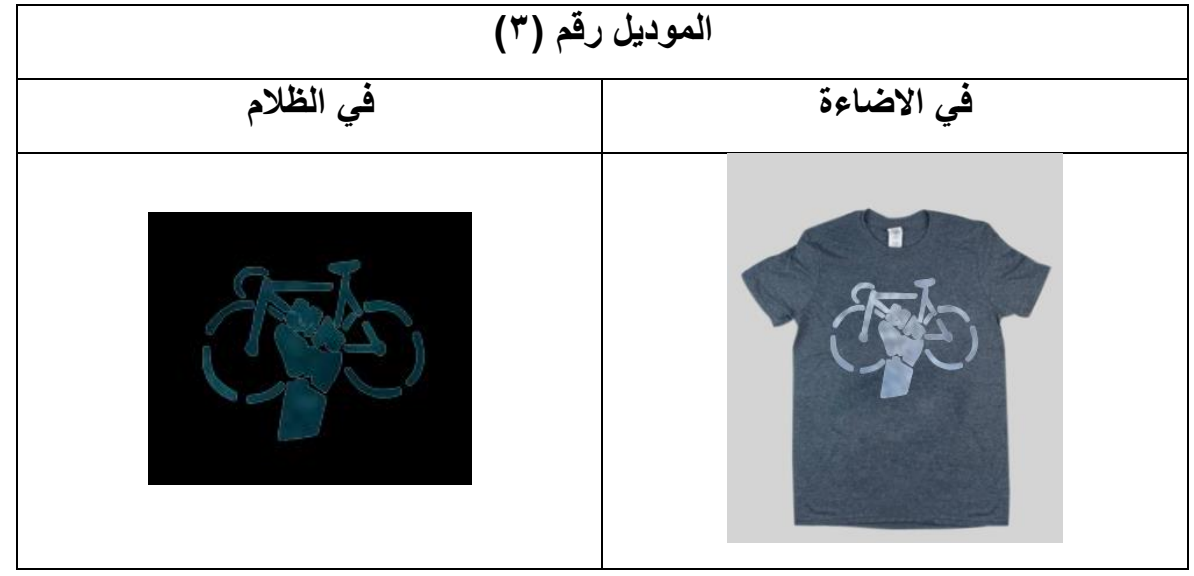


(ب)(القطع المنفذة لفئة الاناث: - (ب)

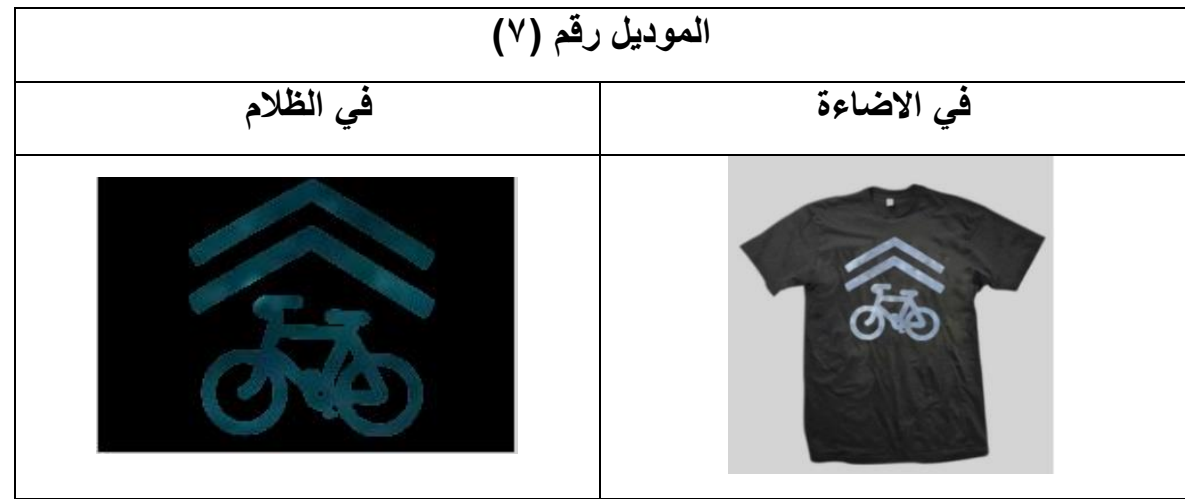

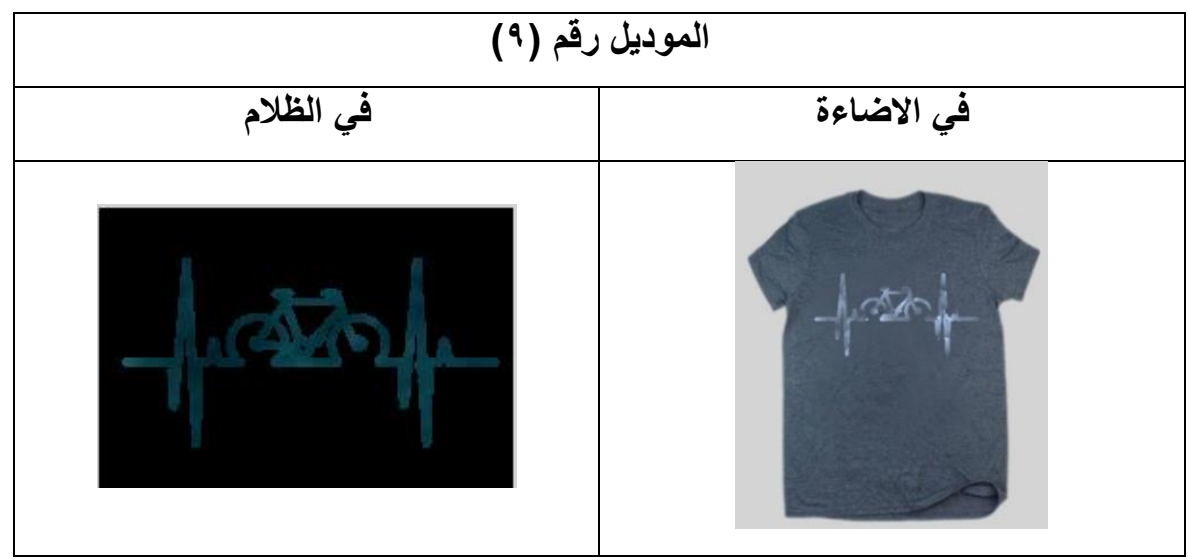

وتم ذللك عن طريق استخدام ألو ان بجمينت زيت وخلطها بالمادة المضيئة وهى مسحوق فلورى(فسفورى) وتفريغ الوحدات المنفذة وطباعتها بأسلوب الاستتسل التقليدي ثم تعرض القطعة المنفذة بتقنية الطباعة المضيئة لمجف هوائى ساخن لفترة

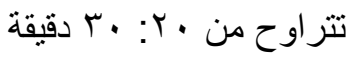
ثم تم تعرض القطع المنفذة لمكبس حر اري على درجة . . ب درجة وذللك لمدة ؟:0 دقائق لتجنب حدوث تغير فى اللون فيما ـ تم تحكيم القطع المنفذة و عرضها على المستهلكين (قائدي الدراجة الهو ائية) للتأكد من مدى ملائمه القطع الملبسية المطبو عة بتقنية الطباعة المضيئة لاحتياجاتهم ومدى قبولها

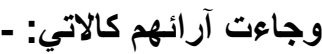
جدول (r) آر اء المستهلكين في التصميمات المنفذة وفق للصياغات التصميمية المنفذة على القطع (ن= ؟ ؟)

\begin{tabular}{|c|c|c|}
\hline معامل الجودة & التصميم & المستهلكين \\
\hline $9 \wedge, 0 Y$ & التصميم 1 & \multirow{2}{*}{ الذكور (ن= 0 (1) } \\
\hline $99, Y 7$ & التصميحץ & \\
\hline $9 \wedge, 7 \vee$ & التصميم V & \multirow{2}{*}{ الإنات (ن= 9 9) } \\
\hline $9 \Lambda, Y r$ & التصميم 9 & \\
\hline
\end{tabular}




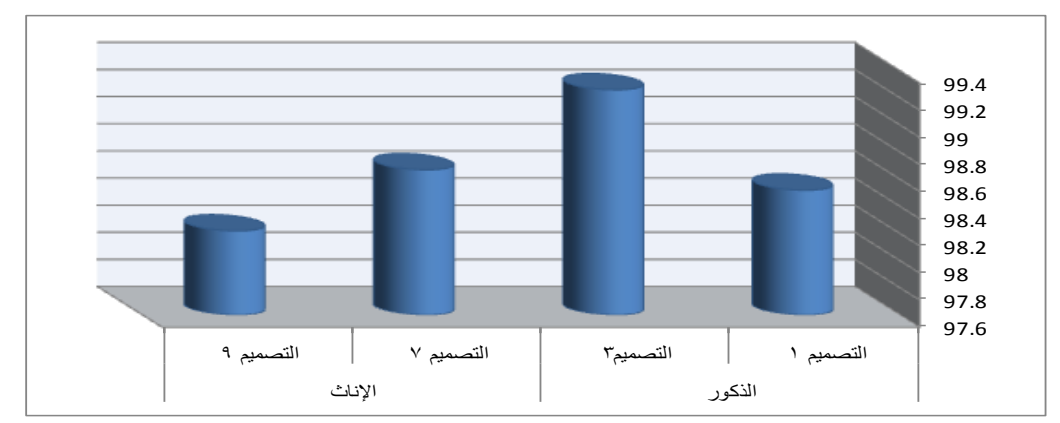

شكل (r) آراء المستهلكين في التصميمات المنفذة وفق للصياغات التصميمية المنفذة على القطع (ن= ؟ ؟)

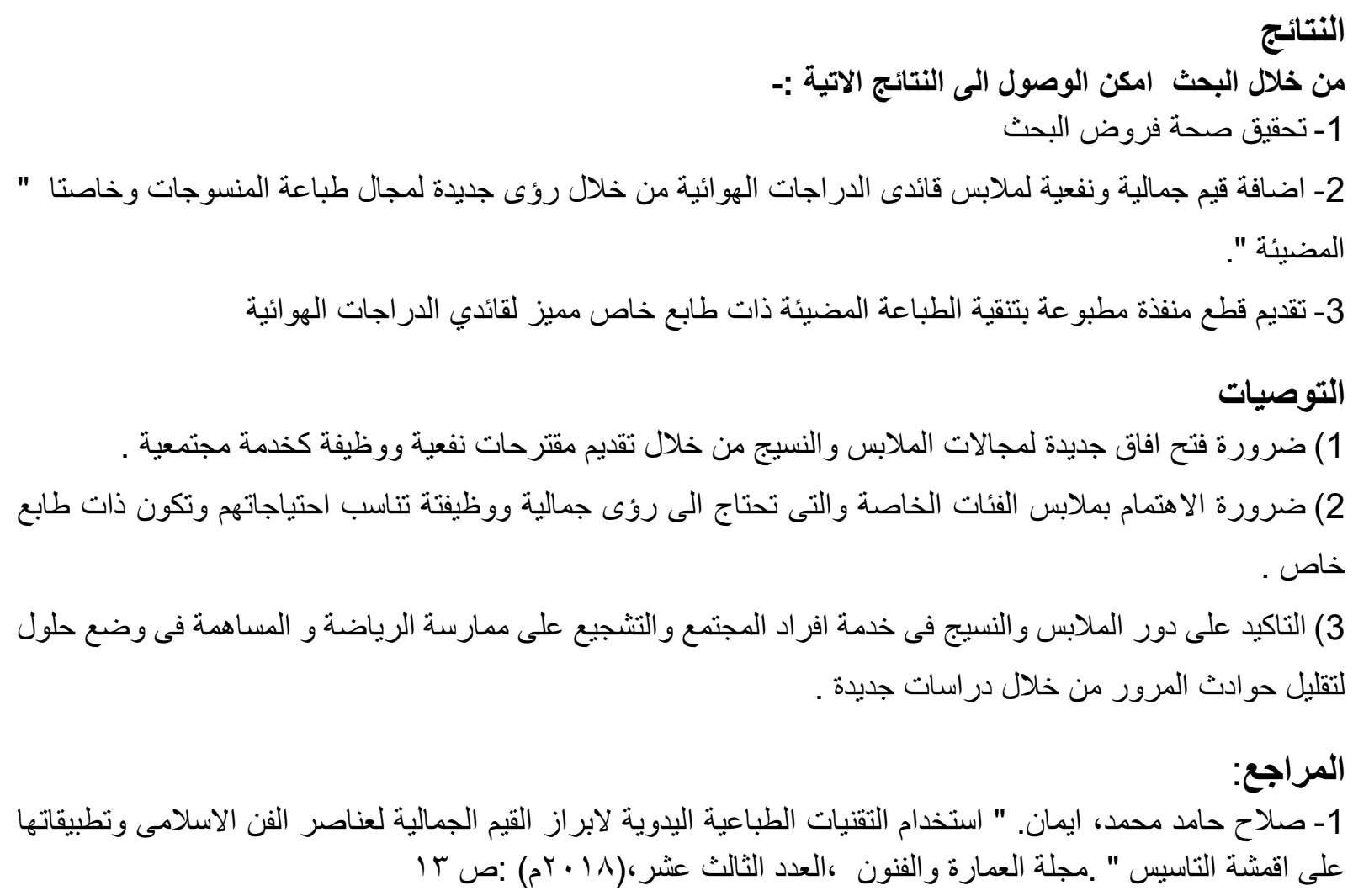

1- salah hamid muhamad, 'iiman. "asitikhddam taqniat altibaeat alyadawiat li'iibraz alqiam aljamaliat lieanasir alfini al'iislamii watatbiqatiha fi tasis al'aqmsha". majalat aleamarat walfunun, aleadad alththalith eshr, (2018 m): s 13

2- حامد محمد الحسينى سرحان ، زينب. " امكانية الاستفادة من اغطية الر أس في العصور الاسلامية في ابتكار تصميمات

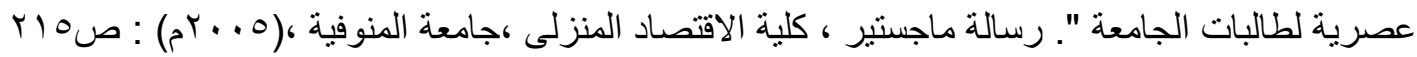

2- hamid muhamad alhusayni sarhan , zynb. "'imukaniat alaistifadat min alhijab fi aleasr al'iislamii fi aibtikar tasamim hadithat litalabat aljamieat". risalat majstyr kuliyat alaiqtisad almanzilii jamieat alminufiat $2005 \mathrm{~m} \mathrm{~s} 215$

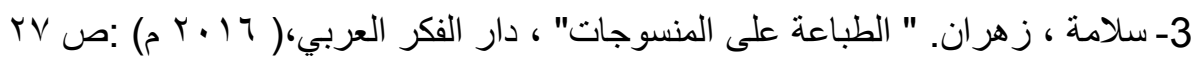

3- salamat , zahran. "altabaeat ealaa alminsujat" dar alfikr alearabiu (2016): s. 27

4- محمود عثمان ، سهير - فكرى جمال ، داليا - سعد انور، ندى. "تقييم ملابس اطفال مواكبة لاتجاهات الموضة العالمية

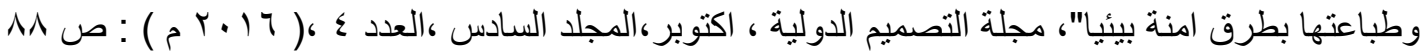
4- mahmud euthman, sahir, fikri jamal, daliaan, saed 'anwar, nda. "tqiim malabis al'atfal alty tawakib aitijahat almawdat alealamiat watibaeataha bituruq aminat byyyaan" , majalat altasmim alduwaliat, 'uktubar, almujalid alssadis , aleadad 4 , (2016 m): 88 


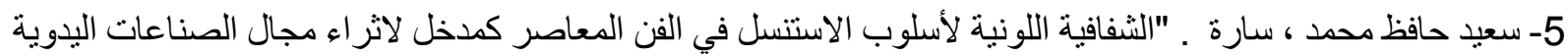

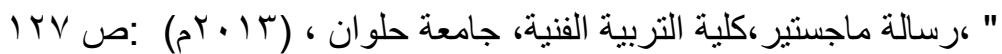

5- saeid hafiz muhamad, sar. "alrsalat allawniat li'uslub alaistansal fi alfan almueasir kamudkhal lathra' alsinaeat alydawi" , risalat majsitir , kuliyat altarbiat alfaniyat , jamieatan hulwan , (2013 m): s 127

6- سيد محمد حسن ، شرين - احمد سيد، سهام. "استخدام التقنيات الذكية ذات التحكم الونى فى تصميم الازياء " ، مجلة

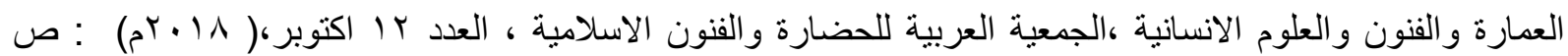

$r \cdot \Lambda, r \cdot v$

6- sayid muhamad hasan, sharin - 'ahmad syd, siham. "asitikhdam altaqniat aldhakiyat dhat altahakum alwunaa fa tasmim alazya"' , majalat aleamarat walfunun waleulum al'iinsaniat , aljameiat alearabiat lilhadarat walfunun al'iislamiat , aleadad 12 'uktubar , (2018 m): s 307 , 308 7- احمد حيزة ، عبد الوهاب ."تكنولوجيا طباعة المنسوجات القطنية " بحث منشور ،ا كادمية البحث العلمى

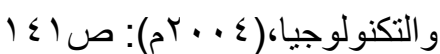
7- 'ahmad hiazat, eabd alwhab. "tknulwjia tibaeat almansujat alqatnia" bahath manshur , a kadimiatan albahth aleulmaa waltiknulujia , (2004 m): s 141

8- احمد عمران ، عفاف ـ "استحداث مجلات ابداعية بالتوليف بين اسلوبى الطباعة بالاستنسل والثاشة الحريرية"،مجلة

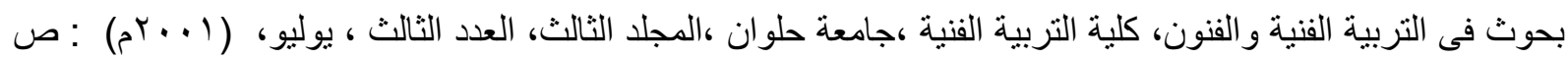

8- 'ahmad eimran, eafaf. "aisitihdath majallat aibdaeiat bialtawlif bayn asluba altabaeat bialaistansal walshashat alhariria" majalatan bihawth fa altarbiat alfaniyat walfunun , kuliyat alfunun , jamieatan hulwan , almujalid alththalith, aleadad alththalith, yuliu , (2001 m): s 243

9- شاكر عبد الفتاح عفيفي ، غادة . " المزج بين طباعة المنسوجات والتطريز في تصميم اقشة المفروشات باستخدام

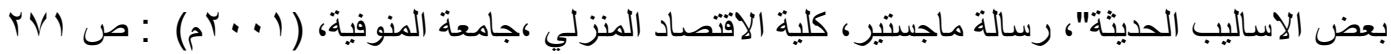

9- shakir eabd alfattah eafifi , ghad. "almizaj bayn tibaeat almansujat waltatriz fi tasmim al'aqmishat almafrushat bed al'asalib alhadith" , risalat majsitir , kuliyat alaiqtisad almanzilii , jamieatan almunufiat, (2001 m): s 271

10- السعيد مصطفى مدين، فاطمة . " استخدام الطباعة بالإزالة في اثراء القيم الجمالية لملابس الاطفال لخدمة

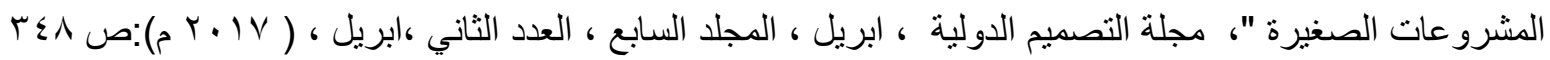

10- alsaeid mustafaa madyan , fatima. "asitikhdam altabaeat bial'iizalat fi athra' alqiam aljamaliat limulabis al'atfal alsaghirat liltabaei" , majalat altasmim alduwaliat , 'abril , almujalid alssabie , aleadad alththani , 'abril , (2017 m): s 348

11- محمد السيد عامر ، مها . " طباعة المنسوجات فى خدمة المجتمع " ، المؤتمر السنوي ( العربي السادس ـ الدولي

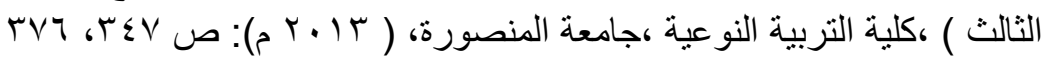

11- muhamad alsyd eamir , maha. "tbaeat almansujat fa khidmat almjtme" , almutamar alsanawiu (alerabiu alssadis - alduwaliu althalth), kuliyat altarbiat, jamieat almansurat , (2013 m): s 347,376

12- عبد الله الجمل ، محمد ـ "الملابس الذكية : التاريخ" التقنيات المستقبل " مجلد ادارة منظومة الملابس الجاهزة ،الحملة

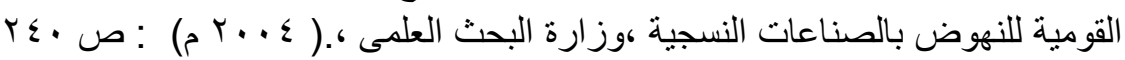
12- eabd allah aljamal , muhmd. "almalabis aldhkyt: altarykh" altaqniat almustaqbalia "mjld 'iidarat manzumat almalabis aljahizat, alhamlat alqawmiat lilnuhud bialsinaeat alnasjiat , wizarat albahth aleulmaa ,. (2004 m): s 240 
13- مرسى ، محمود ـ "خامات فنية و اقمشة حديثة تستخدم فى المنسوجات الذكية" ، مجلد النسخة المصرية ،المعهد

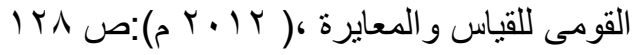
13- mrsa , mahmud. "khamat faniyatan waiqmashat hadithat tustakhdam fa almansujat aldhkya" , mujalad alnuskhat almisriat, almaehad alqawmaa lilqias walmueayirat , (2012 m): s 128

14- محمد ماضي ، نجلاء - عباس محمد منولى الجو هري، رشا ـ "توظيف اقمشة المخرمات فى استحداث تصميمات طباعية كمدخل تجريبى للطباعة اليدوية لخدمة الصناعات الصغيرة "، مجلة الاسكندرية للتبادل العملى ،مجلد هب م ، العدد

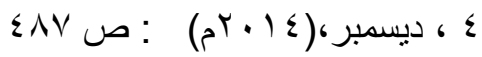

14- muhamad madi , nujala' - eabbas muhamad mutualaa aljawhari, rsha. "twzif 'iisdar almukharamat fa aistihdath nasharat tubbaeiat kamadkhal tijribaa liltibaeat alyadawiat likhidmat alsinaeat alsaghiri" , majalat al'iiskandariat liltabadul aleamlaa , mujalad 35 , aleadad 4 , disambir , (2014 m): s 487

15- عفيفى محمد، نهال . "استخدام التقنيات الحديثة للمنسوجات الذكية فى تحسين الاداء الوظيفى للملابس" ، رسالة

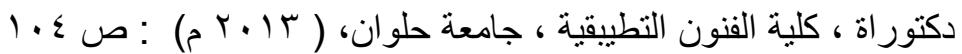
15- eufifaa muhamad, nihal. "asitikhdam altaqniat alhadithat lilmansujat aldhakiyat fi tahsin al'ada' alwazifyaa llmlabs", risalatan dukturat, kuliyat alfunun altatyibqiat, jamieatan hulwan , (2013 m): s 104

16- محمد عكاثشة الصايغ ، هبة . "استخدام طرق الطباعة و الصباغة المختلفة لإلهام مصمم ملابس السيدات بما يناسب

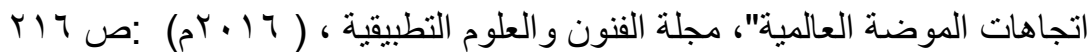

16- muhamad eakkashat alssayigh , huba. "asitikhdam turuq altibaeat walsabaghat lidaykurat alsayidat aitijahat aitijahat almawdat alealamia" , majalat alfunun waleulum altatbiqiat , (2016 m): s 216 